\title{
How to Maximize Bedside Teaching in Our Busy World
}

Vijay Daniels MD, MHPE, FRCPC

\begin{abstract}
About the Author
Vijay Daniels is an associate professor and clinician educator in the Division of General Internal Medicine at the University of Alberta in Edmonton, Alberta. He is the associate program director (assessment) for the Internal Medicine Residency Program and the director of clinical assessment for the MD program at the University of Alberta. Correspondence may be directed to vdaniels@ualberta.ca.
\end{abstract}

\section{Summary}

Bedside teaching is becoming less frequent. A lack of attending physicians' time and perceived teaching skill, as well as concerns regarding the impact of bedside teaching on the relationship with patients have been cited as barriers to bedside teaching. The purpose of this paper is to offer some tips on how to increase the frequency and quality of bedside teaching in light of these barriers. The main recommendations are to 1) be explicit about the competencies around which you are teaching; 2) incorporate bedside teaching into your daily workflow, allowing the available cases and patients to dictate the learning competencies; and 3) use a framework that incorporates published teaching tools to guide your bedside teaching.

The first step of this framework is preparation, which involves choosing the most appropriate teaching competency (history-taking, physical exam, clinical reasoning, or decision-making) based on the learner, case, and patient. Next is delivery, including orienting learners and patients to the task, choosing the instructional modality that fits the competency (such as One Minute Preceptor, SNAPPS, or Mini-CEX), and then debriefing and providing feedback. The final step is reflection on the teaching session, which can include peer observation.

\section{Résumé}

L'enseignement clinique est de moins en moins fréquent. Le manque de temps et d'aptitudes pour enseigner du côté des médecins, ainsi que certaines préoccupations quant aux répercussions de l'enseignement clinique sur la relation avec les patients sont des éléments que l'on pointe comme étant des obstacles. Cet article a pour but d'offrir des conseils permettant d'augmenter la fréquence et la qualité de l'enseignement clinique en tenant compte de ces obstacles.

Voici les principales recommandations : 1) soyez clair et précis quant aux connaissances enseignées; 2) intégrez l'enseignement clinique au quotidien dans votre travail en saisissant les occasions de cas et de patients qui se présentent pour enseigner; et 3) dotez-vous d'une structure qui intègre des outils pédagogiques officiels pour guider votre enseignement clinique.

La préparation constitue la première partie de cette structure. Elle repose sur le choix des connaissances les plus indiquées à enseigner (l'anamnèse, l'examen physique, la résolution des problèmes cliniques ou la prise de décision) selon l'apprenant, le cas et le patient. La partie suivante est celle de la transmission des connaissances. C'est à cette étape que l'on oriente l'apprenant et le patient au regard de l'exercice, que l'on choisit l'outil pédagogique à utiliser selon les connaissances à transmettre (comme One Minute Preceptor, SNAPPS ou Mini-CEX), puis que l'on fait un compte rendu oral de la séance et que l'on procure de la rétroaction. La dernière étape consiste en une réflexion sur la séance d'enseignement, qui peut s'accompagner d'une évaluation par des pairs. 


\section{Introduction}

I am walking onto our medicine wards to start a two-week stint attending on the clinical teaching unit. I have already heard a bit about the new patients in morning report, so when the team gathers to review the patients admitted overnight, I say, "Let's head to the bedside to review the case and do some teaching." As is often the case, the senior resident looks up from the chart and asks, "You want to go to the bedside?" Sound familiar?

There are many barriers to bedside teaching. Williams and colleagues ${ }^{1}$ conducted focus groups of trainees at Boston University and identified the following main barriers: lack of time from attending physicians due to busy clinical and nonclinical duties, lack of teaching skill among attending physicians, overreliance on technology, possible lack of respect for patients during the teaching process, and possible threat to patient confidence in the trainee when mistakes are pointed out. The purpose of this paper is to offer some tips on how to increase the frequency and quality of bedside teaching in light of these barriers. The three main recommendations are as follows: 1) to be explicit when doing bedside teaching, 2) to make bedside teaching part of one's routine workflow, and 3) to use a framework when approaching bedside teaching.

\section{Bedside Teaching - What It Is and Which Competencies Are Best Addressed With It}

Bedside teaching can be thought of as any teaching that relates to direct patient care. With this definition, the following four competencies could be the focus of bedside teaching: history taking (including communication, attitudes, and professionalism), physical examination skills, clinical reasoning (incorporating the data into a diagnosis and differential diagnosis), and clinical decision-making (based on the diagnosis and differential diagnosis, how to further investigate or manage the patient). Although some might define bedside teaching as just history taking and physical examination, we will use this broader definition to help us understand the purpose of some published techniques to bedside teaching.

\section{Be Explicit When Doing Bedside Teaching}

How often have you engaged your trainees in a discussion around an interesting case and then later overhear them say, "We never get any teaching"? For whatever reason, trainees do not always perceive that, when attending physicians model history taking or discuss clinical reasoning, this is bedside teaching, and can be a very effective method. A powerful impact can be made when a teacher says, "This is a tough case. Let's do some teaching on clinical reasoning to work through it." or "Seeing the JVP is not easy and comes with practice. Let's do some physical exam teaching." First, the teacher admitting the difficulty of clinical medicine can put a trainee at ease. Second, the trainees become primed and engaged. Finally, when done often enough, teachers can monitor the competencies they like to teach. If a teacher is explicit about "teaching on clinical reasoning" every day for a week, they might quickly realize it is time to focus on another competency, such as observing a learner take a patient's history or perform a physical examination.

\section{Make Bedside Teaching a Part of Routine Workflow}

Although many programs institute dedicated bedside teaching rounds to ensure that bedside teaching occurs, there are two problems with this. First, the addition to routine workflow adds to the workload of already busy physicians. Second, it is

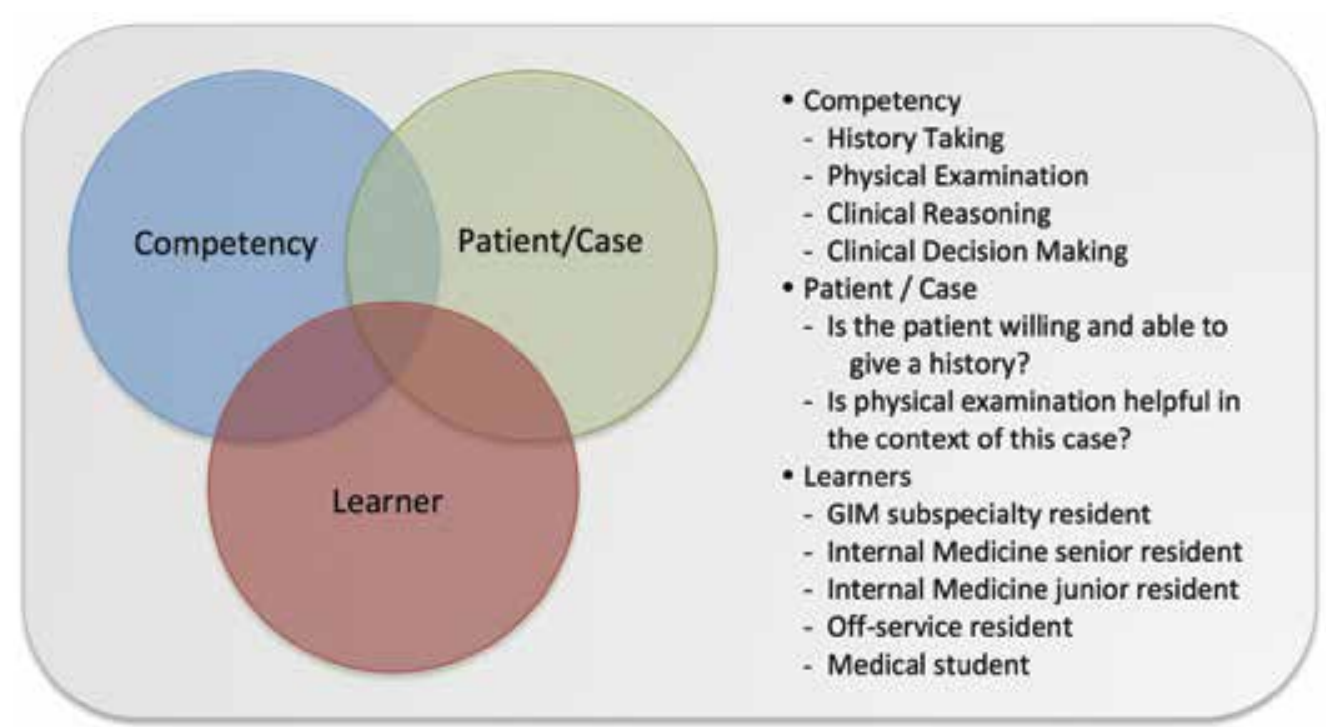

Figure 1. 
one of the foundational pedagogical principles that skills are best learned in the context in which they will later be applied. Physicians use the physical examination to augment the history when diagnosing the patient. Therefore, it is best to learn the physical examination of heart failure in the context of a patient presenting with suspected heart failure. For these reasons, bedside teaching should be incorporated into routine workflow; that is, in tandem with reviewing a case with a trainee.

\section{Framework For Bedside Teaching}

Ramani ${ }^{2}$ published a set of 12 tips to improve bedside teaching and divided them into activities before, during, and after the teaching session. Rather than reiterate the 12 tips, I will summarize each of the three stages.

\section{Before}

Preparation involves knowing the case and the trainee and considering the fit between these and the learning competency (see Figure 1). For example, if you have an orthopedic resident with you, bedside teaching could involve history or physical examination of a patient with heart failure, or clinical reasoning of a patient with delirium; it would be less ideal to use a case of tricyclic antidepressant overdose for this particular trainee. After considering the fit between the case, the trainee, and the competency, the attending needs to orient the trainees and the patient to the focus and objectives of the session and must obtain consent from the patient. As previously mentioned, the lack of respect for patients was identified as a barrier to bedside teaching, due to concerns that patients do not like being practiced on or having sensitive issues discussed in front of others. However, a survey at a Veterans Affairs hospital found that $68 \%$ of patients preferred to have the case presentations done at the bedside, and only $6 \%$ disliked bedside teaching. ${ }^{3}$ Hence, most, but not all, patients are willing to have their case presented in front of them and participate in bedside teaching, but this must be confirmed with each patient.

\section{During}

Once the bedside teaching session begins, there are three broad approaches to teaching: instruction, modelling clinical skills, and observation. Instruction is likely the most common approach and involves probing the learners with questions, engaging all learners, and capturing teachable moments. This approach tends to focus on clinical reasoning and clinical decision-making. The One-Minute Preceptor ${ }^{4}$ and SNAPPS 5 are two published techniques that use this approach while reviewing a case. The One-Minute Preceptor involves five steps: 1) Get a commitment from the trainee stating the diagnosis or plan; 2) Probe the trainee to present supporting evidence; 3) Teach some general rules or "take-home points" that are learning issues from the case that can be applied to other cases; 4) Reinforce what the trainee has done well; and 5) Provide constructive feedback. ${ }^{4}$

SNAPPS is a different approach and outlines what the trainees do during a case review. It stands for the following: summarize history and findings $(\mathrm{S})$, narrow the differential $(\mathrm{N})$, analyze the differential (A), probe the preceptor about uncertainties $(\mathrm{P})$, plan management $(\mathrm{P})$, and select case-related issues for selfstudy (S). Both One-Minute Preceptor and SNAPPS involve summarizing the case, discussing the key features that support or refute a diagnosis, and discussing the management plan. The One-Minute Preceptor is preceptor driven and requires no orientation for the trainee. SNAPPS is learner driven, with the learner probing the preceptor for areas of uncertainty and then selecting a case-related issue to review; this method requires orienting both the preceptors and the trainees.

In a small study of two videotaped case reviews, the One-Minute Preceptor approach increased the ability of the preceptor to diagnose the medical condition and increased his/her confidence in rating the trainee's presentation skills, clinical reasoning skills, and fund of knowledge pertaining to a case, compared to the traditional case review. ${ }^{4}$ In a study of SNAPPS, learners who were taught this technique discussed a broader differential, justified it more, and verbalized far more questions and uncertainties about the case. ${ }^{5}$ Hence, these two approaches are excellent for teaching and testing clinical reasoning and decision-making.

The second approach to bedside teaching involves the clinical teacher intentionally modelling their interactions with the patient or modelling clinical reasoning as a form of instruction. Breaking bad news is an important part of a general internist's practice. I use these unfortunate opportunities to model my approach to trainees. Before we enter the patient's room, I prime the trainee(s) that I will model how I break bad news. I ensure the patient is comfortable having trainees in the room and generally limit the number, given the sensitive nature of the situation. After I have finished and answered the patient's or family's questions and left the room, I then debrief with the trainee(s) about how they felt it went, and how what they saw relates to what they were taught, with respect to breaking bad news. In my experience, most of my colleagues view this role modelling as one of the most important aspects of bedside teaching, but bookending it with priming the trainee(s) before entering the room and debriefing them afterwards really drives it home.

The last approach is observation of a trainee and the two competencies that lend themselves best are history taking and physical examination. This instructional activity can also be an assessment activity if scored and documented-which is the which is the basis of the Mini-Clinical Evaluation Exercise (Mini- 
CEX). ${ }^{7}$ The Mini-CEX involves approximately 15 minutes of observation and 5 minutes of feedback; however, the length of observation used as an instructional activity can be tailored to the task. To incorporate the Mini-CEX into daily workflow, one can make it a part of the case review.

Instead of listening to a trainee present the history and physical exam data on a newly admitted patient, the preceptor asks another learner to demonstrate one of these skills. To observe a focused physical exam, the trainee who admitted the patient shares the history. Then the preceptor asks a second trainee to state the most likely diagnosis and differential and then perform a focused physical exam based on what they suspect. The entire team observes the physical, after which the trainee who admitted the patient shares their findings, and the team compares the two.

To use this approach for history taking, a learner who is unaware of the patient's diagnosis is given only the presenting complaint (e.g., shortness of breath) and then asked to take a focused history. Once the history is completed, the team compares notes between this and the admitting trainee's history and resolves any discrepancies by clarifying with the patient.

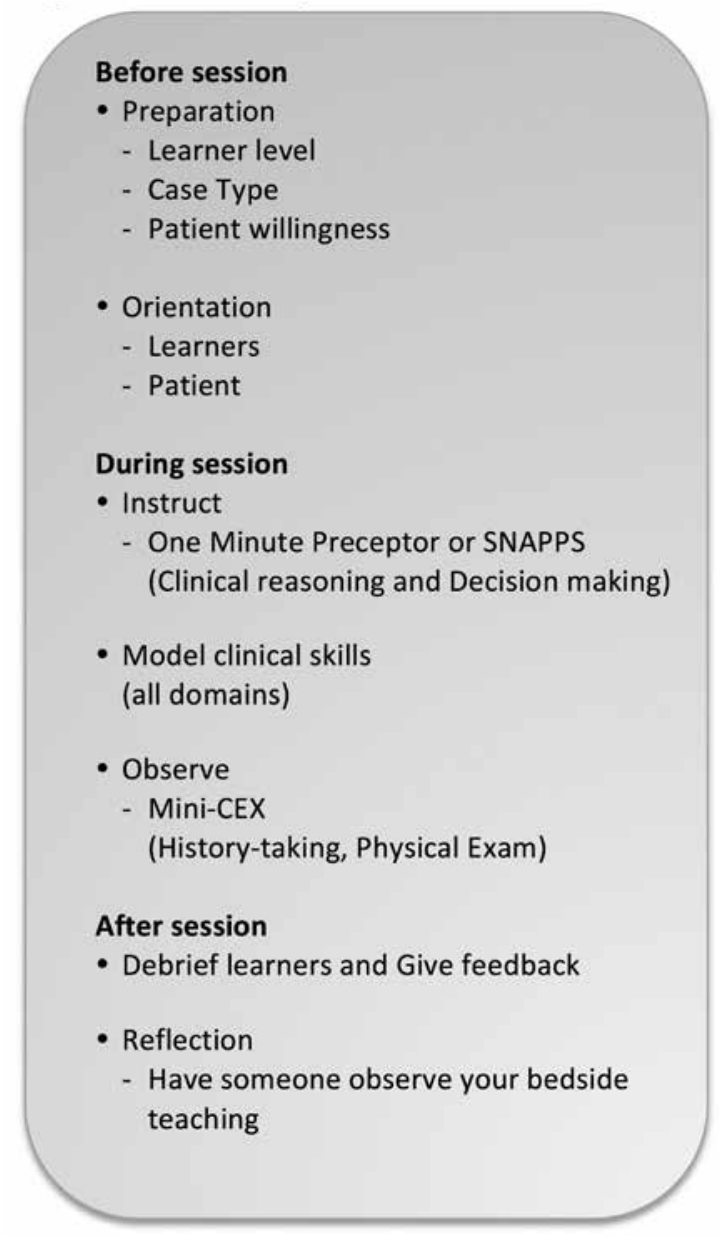

Figure 2.

\section{After}

Immediately after any teaching session, learners are asked if they have any questions (debriefing) and are then given specific, behaviour-based, constructive feedback. The approach to giving feedback is beyond the scope of this paper, but there are excellent reviews of this, such as the one by Ramani and Krackov. ${ }^{8}$ As the teacher, a second critical step is to reflect on what went well and what could have been done better and to use these reflections to improve future sessions. One powerful way to do this is to have a colleague observe you. Beckman ${ }^{9}$ reported on experiences of a peer-review bedside teaching project at the Mayo Clinic, and one of the key findings was how valuable peer review was to both the observed and the observer. Colleagues of mine at the University of Alberta have developed a tool for highlighting the domains of feedback when observing bedside teaching, which has greatly helped the observation and feedback process. This is available upon request.

\section{Summary}

To summarize, being explicit about bedside teaching can prime learners and allow teachers to reflect on their teaching. Incorporating bedside teaching into daily workflow can increase its frequency and enhance its value to learners. And, finally, using the aforementioned framework (summarized in Figure 2) can be helpful for improving bedside teaching.

\section{Acknowledgements}

Thanks to Drs. Mahua Ghosh, Cheryl Goldstein, and Jennifer Ringrose for their feedback on the workshop content that was the basis for this paper.

Conflict of interest: None declared.

\section{References}

1. Williams KN, Ramani S, Fraser B. Improving bedside teaching: findings from a focus group study of learners. Acad Med 2008;83:257-64.

2. Ramani S. Twelve tips to improve bedside teaching. Med Teach 2003;25:112-5.

3. Fletcher KE, Rankey DS, Stern DT. Bedside interactions from the other side of the bedrail. J Gen Intern Med 2005;20:58-61.

4. Aagaard E, Teherani A, Irby DM. Effectiveness of the one-minute preceptor model for diagnosing the patient and the learner: proof of concept. Acad Med 2004;79:42-9.

5. Wolpaw TM, Wolpaw DR, Papp KK. SNAPPS: a learner-centered model for outpatient education. Acad Med 2003;78:893-8.

6. Wolpaw T, Papp KK, Bordage G. Using SNAPPS to facilitate the expression of clinical reasoning and uncertainties: a randomized comparison group trial. Acad Med 2009;84:517-24.

7. Norcini JJ, Blank LL, Duffy FD. The mini-CEX: a method for assessing clinical skills. Ann Intern Med 2003;138:476-81.

8. Ramani S, Krackov SK. Twelve tips for giving feedback effectively in the clinical environment. Med Teach 2012;34:787-91.

9. Beckman TJ. Lessons learned from a peer review of bedside teaching academic medicine 2004;79:343-6. 